\title{
Evaluation of infliximab as second-line treatment of acute graft versus host disease -validating response on day 7 and 28 as predictors of survival
}

\author{
Marietta Nygaard $\mathbb{1}^{1} \cdot$ Niels Smedegaard Andersen ${ }^{1} \cdot$ Claus Ernst Moser $^{2} \cdot$ Gitte Olesen $^{1} \cdot$ Ida Marie Schjødt $^{1}$ • \\ Carsten Heilmann ${ }^{1} \cdot$ Henrik Sengeløv ${ }^{1}$
}

Received: 13 September 2017 / Revised: 19 December 2017 / Accepted: 31 December 2017 / Published online: 1 February 2018

(c) Macmillan Publishers Limited, part of Springer Nature 2018

\begin{abstract}
Several immunosuppressive drugs have been proposed for second-line treatment of steroid-refractory acute graft versus host disease (aGvHD) after allogeneic hematopoietic stem cell transplantation. However, the studies on these drugs are small, retrospective, uncontrolled and use different endpoints. Therefore, it remains unknown which treatment is superior. We retrospectively evaluated 68 consecutive patients treated with infliximab for aGvHD. We adhered to recently proposed guidelines for aGvHD trials and thus evaluated response on day 7 and 28. Furthermore, we assessed the composite endpoint 6 months freedom from treatment failure (6MFTF). The majority of patients had grade III-IV aGvHD. We found that 41 patients $(60 \%)$ responded on day 7 and 31 patients $(46 \%)$ on day 28 . Twenty-four patients $(35 \%)$ achieved 6 MFTF. The main reasons for failure within 6 months were death $(n=31)$ or additional immunosuppression $(n=16)$. By six and 24 months, 44 and 34\% of the patients were alive respectively. Patients with response to infliximab on day 7 and 28 had significantly higher overall survival (OS) probability than non-responders. We show that response on day 7 and 28 identifies high and low risk groups. Patients who fail to respond should be identified early and offered alternative therapy.
\end{abstract}

\section{Introduction}

Acute Graft versus Host Disease (aGvHD) is a common and severe complication to hematopoietic stem cell transplantation (HSCT). There is consensus that first-line treatment is $1-2 \mathrm{mg} / \mathrm{kg}$ glucocorticoid; however for steroid-refractory patients, it remains unknown which treatment option is superior [1].

Several second-line therapies have been proposed; most of which add further immunosuppression and thus increase risk of infection and relapse. Most studies show some effect

Electronic supplementary material The online version of this article (https://doi.org/10.1038/s41409-018-0099-3) contains supplementary material, which is available to authorized users.

Marietta Nygaard

marietta.nygaard@regionh.dk

1 Department of Hematology, National University Hospital, Rigshospitalet, Denmark

2 Department of Clinical Microbiology, National University Hospital, Rigshospitalet, Denmark of the studied second-line agent, but the prognosis remains poor with only approximately $50 \%$ of patients surviving 6 months [1].

Comparison of studies is complicated by the small number of studied patients, lack of control groups, inconsistent treatment schedules and different criteria for response assessment [2]. Recent guidelines for response assessment in aGvHD studies recommend evaluating treatment response at fixed timepoints [3, 4]. Furthermore, a composite endpoint, 6 months freedom from treatment failure (6MFTF), is increasingly used $[5,6]$.

In our center, we have used the tumor necrosis factor $\alpha$ (TNF- $\alpha$ ) inhibitor infliximab as second-or further-line treatment for aGvHD since the year 2000. TNF- $\alpha$ is significantly increased in patients with aGVHD [7], and inhibition of TNF$\alpha$ may potentially control aGVHD [8]. Inhibition of TNF- $\alpha$ has been suggested in all phases of aGvHD treatment; as prevention $[9,10]$, as part of primary aGvHD treatment [1115], and most commonly as treatment for steroid-refractory or steroid-dependent aGVHD [16-25].

In this retrospective evaluation, we adhere to the recently proposed guidelines for response assessment. We intend to supplement earlier evidence of the effect of infliximab as 
second-line-treatment and to validate if response on day 7 and 28 after second-or-further line treatment is predictive of survival as proposed in above referred guidelines. To our knowledge, this is the largest study on patients with mainly severe steroid-resistant aGvHD treated with infliximab. Hopefully this will further elucidate the role of infliximab in the treatment of aGvHD.

\section{Patients and methods}

A single investigator ( $\mathrm{MN}$ ) reviewed the records of all patients treated with infliximab between 01-01-2000 and 17-06-2014. All patients gave informed consent for use of data and the study was conducted according to the directions of the regional Ethics Committee. Myeloablative conditioning regimens were total body irradiation (TBI) 12 Gy with cyclophosphamide $120 \mathrm{mg} / \mathrm{kg}$ or etoposide phosphate $1800 \mathrm{mg} / \mathrm{m}^{2}$ or busulphane $12.8 \mathrm{mg} / \mathrm{kg}$ plus cyclophosphamide $120 \mathrm{mg} / \mathrm{kg}$. Non-myeloablative regimens were TBI $200 \mathrm{cGy}$ (or in a few cases 300 or $400 \mathrm{cGy}$ ) combined with fludarabine $90 \mathrm{mg} / \mathrm{m}^{2}$ or fludarabine $90 \mathrm{mg} /$ $\mathrm{m}^{2}$ without TBI. Graft versus host disease prophylaxis was cyclosporine A (CsA) with short-course methotrexate in myeloablative HSCT and tacrolimus (TAC) or CsA and mycophenolate mofetil (MMF) in non-myeloablative HSCT. Donors were $10 / 10$ or $9 / 10$ human leucocyte antigen (HLA) identical siblings or HLA-matched unrelated donors; except for two with single antigen mismatch.

\section{Acute GVHD diagnosis}

Both classical aGvHD, occurring within 100 days after HSCT, and persistent or late-onset aGvHD were included. Gastro-intestinal GvHD was diagnosed by histological examination of a sigmoideum biopsy. Skin GVHD was diagnosed by presence of a typical maculopapular rash. Liver GVHD was diagnosed by increase in serum bilirubin without other possible causes. Grading of aGvHD was assessed by standard criteria [26].

Insufficient response to standard high-dose $(1-2 \mathrm{mg} / \mathrm{kg})$ glucocorticoid treatment was defined as aggressive progression of de novo aGvHD grade within 3 days, no response after 1 week of therapy or inability to taper glucocorticoid dose after an initial response. If glucocorticoids had been tapered below $0.5 \mathrm{mg} / \mathrm{kg}$ before reoccurrence of aGvHD, the day of increased glucocorticoid dose was considered the start of the current aGvHD episode.

\section{Response assessment}

Baseline for aGvHD grading score was the day infliximab was started. Overall response of aGvHD was assessed on day
7 and 28 after start of infliximab treatment. Complete response (CR) was defined as resolution of all indicators of aGvHD, very good partial response (VGPR) was an approximation of CR as described by Martin et al. [4]. Partial response (PR) was improvement of one or more grades in any affected organ without progression or de novo aGvHD in other organs. If progression was noted in any organ or additional treatment was administered, patients were classified as having progressive disease (PD). Change in immunosuppression due to side effects was not considered PD. Both substitution and addition of immunosuppression were at the discretion of the treating physician. Stable disease (SD) was unaltered grading in all affected organs.

On day 7, any response (CR, VGPR or PR) was considered significant treatment effect. On day 28 only CR and VGPR were considered significant treatment effect. We also evaluated 6MFTF where failure was defined as death, relapse of malignancy or need for additional systemic immunosuppression within 6 months $[5,6]$.

\section{Treatment with infliximab}

Infliximab was used off label for steroid-refractory or steroiddependent aGvHD as allowed by the national health authorities. No patient was excluded from start of infliximab treatment due to poor performance status, infection or financial issues. Standard dosage of infliximab was $10 \mathrm{mg} / \mathrm{kg}$ once weekly, but if the patient had PD, an intensified schedule with two doses weekly could be used. Unless severe infections or PD occurred, infliximab was continued until the patient had CR/VGPR.

\section{Infections}

All patients received posaconazole or liposomal Amphotericin $\mathrm{B}$, acyclovir or valaciclovir, and co-trimoxazole or dapsone. If neutrophil count was below $0.5 \times 10^{9} / \mathrm{L}$, ceftazidime or meropenem was administered. When body temperature exceeded $38{ }^{\circ} \mathrm{C}$, blood, urine and sputum cultures were taken followed by preemptive antibiotic administration. Quantitative PCR analysis for CMV in blood was performed weekly, and if positive, valganciclovir, ganciclovir or foscarnet replaced acyclovir/valaciclovir. Verified bacterial, fungal or viral infections were recorded for 6 months after start of infliximab. Occurrence of severe or life threatening/fatal infections was registered according to BMT CTN Data Coordinating center's definition of infection severity (https://web.emmes.com/study/bmt2/public/ Definition/Definitions_of_Inf_Severity.pdf).

\section{Statistics}

Association of baseline variables to day 7 and 28 response and 6MFTF was analyzed using the $\chi^{2}$ test or Fishers exact 
Table 1 Patient characteristics

\begin{tabular}{|c|c|c|}
\hline Characteristics & $N$ & $\%$ \\
\hline Age, mean (range) & 50.2 & $(25-73)$ \\
\hline \multicolumn{3}{|l|}{ Sex } \\
\hline Male & 44 & 65 \\
\hline Female & 24 & 35 \\
\hline \multicolumn{3}{|l|}{ Diagnosis } \\
\hline Acute myeloid leukemia & 18 & 26 \\
\hline MDS & 16 & 24 \\
\hline Acute lymphoid leukemia & 8 & 12 \\
\hline Chronic lymphocytic leukemia & 8 & 12 \\
\hline Chronic myeloid leukemia & 4 & 6 \\
\hline Hodgkins lymphoma & 3 & 4 \\
\hline Non-Hodgkins lymphoma & 6 & 9 \\
\hline Multiple myeloma & 3 & 4 \\
\hline Severe aplastic anemia & 1 & 1 \\
\hline Prolymphocyte leukemia & 1 & 1 \\
\hline \multicolumn{3}{|l|}{ Remission status at HCT } \\
\hline In remission & 47 & 69 \\
\hline Not in remission & 21 & 31 \\
\hline \multicolumn{3}{|l|}{ Conditioning } \\
\hline Myeloablative & 22 & 32 \\
\hline Non-myeloablative & 46 & 68 \\
\hline \multicolumn{3}{|l|}{ Donorrelation } \\
\hline Related & 34 & 50 \\
\hline Unrelated & 34 & 50 \\
\hline \multicolumn{3}{|l|}{ Cell source } \\
\hline Peripheral blood & 54 & 79 \\
\hline Bone marrow & 14 & 21 \\
\hline \multicolumn{3}{|l|}{ Recipient/donor sex } \\
\hline Female/male & 11 & 20 \\
\hline Female/female & 9 & 16 \\
\hline Male/female & 9 & 16 \\
\hline Male/male & 26 & 47 \\
\hline \multicolumn{3}{|c|}{ GVHD profylaxis (at time of aGVHD diagnosis) } \\
\hline CsA & 21 & 31 \\
\hline TCR & 11 & 16 \\
\hline $\mathrm{CsA}+\mathrm{MMF}$ & 15 & 22 \\
\hline $\mathrm{TCR}+\mathrm{MMF}$ & 17 & 25 \\
\hline MMF & 4 & 6 \\
\hline \multicolumn{3}{|l|}{ Overall GVHD grade } \\
\hline Grade II & 17 & 25 \\
\hline Grade III & 33 & 49 \\
\hline Grade IV & 18 & 26 \\
\hline \multicolumn{3}{|l|}{ Organ involvement of aGVHD } \\
\hline Gastrointestinal only & 30 & 44 \\
\hline Gastrointestinal + liver & 11 & 16 \\
\hline Gastrointestinal + skin & 10 & 15 \\
\hline Gastrointestinal + liver + skin & 1 & 2 \\
\hline
\end{tabular}

Table 1 (continued)

\begin{tabular}{lll}
\hline Characteristics & $N$ & $\%$ \\
\hline \multicolumn{1}{c}{ Skin only } & 15 & 22 \\
$\quad$ Liver only & 1 & 2 \\
$\begin{array}{l}\text { Days from HCT/DLI to aGVHD onset. Median } \\
\text { (range) }\end{array}$ & 48 & $(14-337)$ \\
$\begin{array}{l}\text { Days from steroid to infliximab. Median (range) } \\
\begin{array}{l}\text { Number of infliximab doses at day 28. Median } \\
\text { (range) }\end{array}\end{array}$ & 6 & $(1-125)$ \\
$\begin{array}{l}\text { Total number of infliximab doses. Median (range) } \\
\text { (1-9) }\end{array}$ & 4 & $(1-13)$ \\
\hline
\end{tabular}

test for categorical variables and Mann-Whitney's test for continuous variables. Overall survival (OS) probability was estimated by the Kaplan-Meier method with comparison done by the log rank test. Survival probability was estimated with start of infliximab therapy as day 0 . When using day 7 and day 28 as landmarks for impact on survival, only patients alive at that time point were included in the analysis. Statistical tests were two-tailed and a $p$-value $<0.05$ was considered statistically significant. The SPSS ${ }^{\odot}$ software version 22 was used for all statistical analysis.

\section{Results}

Between 01-01-2000 and 17-06-2014, a total of 938 patients received an allogeneic HSCT at our center and of these, 315 (35.8\%) developed grade II-IV aGvHD. Sixtyeight patients $(7.2 \%)$ received infliximab as second-orfurther-line treatment of aGvHD. Patient and treatment characteristics of these patients are shown in Table 1. Three patients developed aGvHD after donor lymphocyte infusion, six patients after a second transplant.

\section{Treatment of aGvHD}

At initial diagnosis of aGvHD, 66 patients received $2 \mathrm{mg} / \mathrm{kg}$ methylprednisolone (MP) or prednisolone. Two patients started on lower doses but were increased to $2 \mathrm{mg} / \mathrm{kg}$ due to progression in aGvHD. When infliximab treatment was initiated, nine patients received less than $1 \mathrm{mg} / \mathrm{kg}$ glucocorticoid due to uncontrolled diabetes $(n=2)$, active CMV infection $(n=1)$ or tapering of prolonged steroid treatment $(n=6)$. Tapering of glucocorticoids had been attempted in $32(47 \%)$ patients before aGvHD progression necessitated increase to $2 \mathrm{mg} / \mathrm{kg}$ again and thereafter infliximab.

At start of infliximab treatment, concomitant immunosuppressive medication was: CsA $(n=21)$, TAC $(n=11)$, $\mathrm{TAC}+\mathrm{MMF} \quad(n=17), \quad \mathrm{CsA}+\mathrm{MMF} \quad(n=15), \quad \mathrm{MMF}$ $(n=3)$, and MMF plus sirolimus $(n=1)$. Four patients received other aGvHD therapies prior to or at the same time 


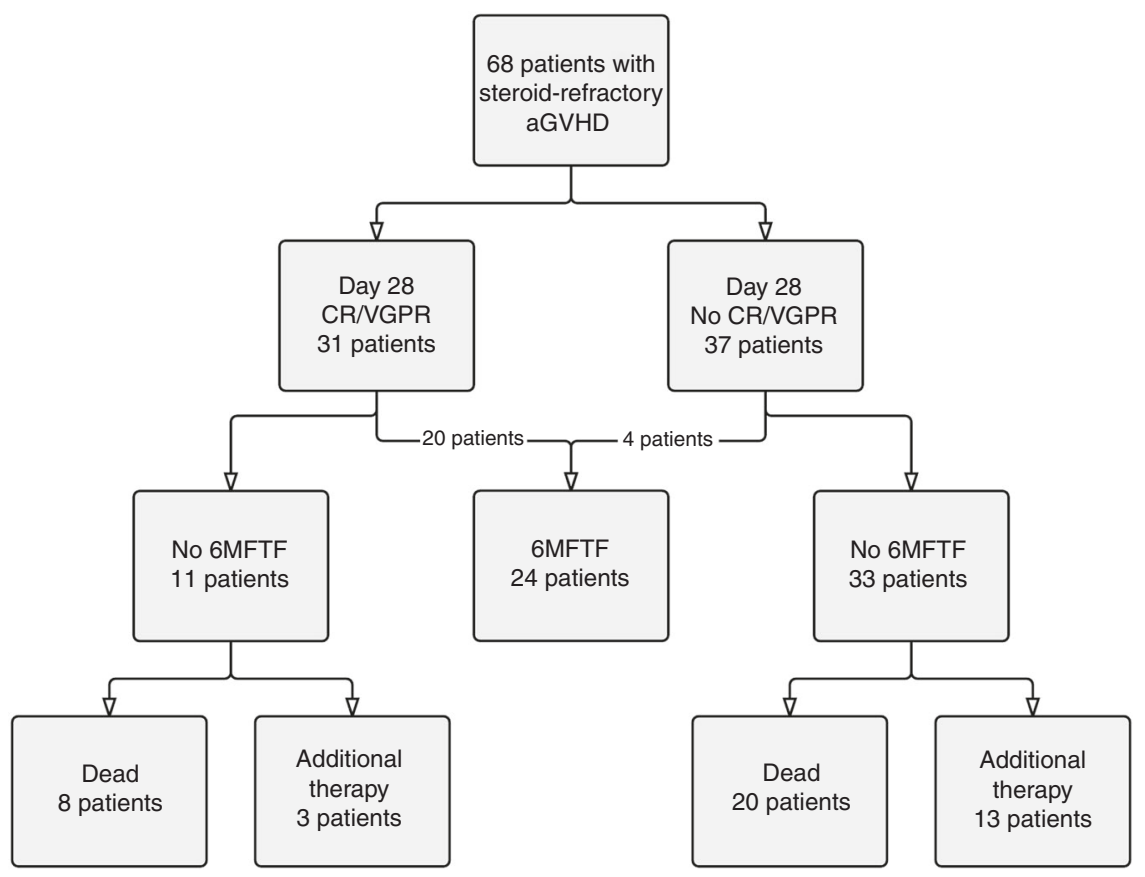

Fig. 1 Flowchart of the course of the patients according to response on day 28

as starting infliximab; antithymocyte globulin (ATG) $(n=2)$, extracorporeal photopheresis $(n=1)$ or ultraviolet phototherapy (UVA1) $(n=1)$.

Median of three infliximab doses (range 1-9) was administered within 28 days. Schedules for administration of infliximab were: standard weekly $(n=24)$, twice weekly $(n=31)$, twice weekly for a total of two doses $(n=7)$ or only one dose $(n=6)$. Infliximab was stopped before day $28(n=53)$ for the following reasons: improvement in aGvHD $(n=29)$, infection $(n=6)$, progression with need for additional treatment $(n=8)$ and death $(n=10)$.

Additional therapy before day 28 was $\operatorname{MMF}(n=4)$, $\mathrm{MMF}+1 \mathrm{~g} \quad \mathrm{MP} \quad(n=1), \quad$ daclizumab + ATG $\quad(n=1)$, rituximab $(n=1)$ or sirolimus $(n=1)$. Additions after day 28 were UVA1 $(n=3), \operatorname{MMF}(n=2)$, sirolimus $(n=1)$, daclizumab $(n=1), 1 \mathrm{~g}$ MP + sirolimus $(n=1)$. Eleven patients continued infliximab after addition of therapy, whereas infliximab had stopped prior to addition in five patients. Eight patients changed immunosuppression due to side effects, usually thrombotic microangiopathy or impaired kidney function.

Glucocorticoid dose was reduced by $50 \%$ in 45 patients after a median of 3 weeks (range 1-8). At 24 weeks, 30 evaluable patients received no glucocorticoid $(n=13), \leq 10$ $\mathrm{mg}$ daily $(n=9)$, and $>10 \mathrm{mg}$ daily $(n=8)$. Overall, glucocorticoids were discontinued in 18 patients with 13 of those eventually free from all immunosuppressive medication.

\section{Response}

On day 7, CR, VGPR or PR was obtained in 41 patients $(60 \%)$, and on day 28 , CR or VGPR was obtained in 31 (46\%) patients. When including PR in the day 28 response, we found a response rate of $66 \%$. Twenty-four patients (35\%) achieved 6MFTF, where the majority had CR/VGPR on day $28(n=20,83 \%)$. Reasons for treatment failure within 6 months were death $(n=31)$ or additional immunosuppression $(n=16)$. See flow chart in Fig. 1. Of the eight patients with additional treatment before day 28 , one had CR on day 28, five had PD and two had died.

The only variable significantly predictive of responses on day 7, day 28 and 6MFTF was grade of aGvHD at start of infliximab treatment (day $7 p=0.001$, day $28 p=0.005$ and 6MFTF $p=0.002$ ). Analysis of other possible baseline predictors of response is shown in supplemental Table 1 . For patients with gastrointestinal involvement, there was a significantly positive association with CR/VGPR on day 28 $(p=0.014)$, but not with other endpoints.

\section{Survival}

At six and 24 months, 44 and $34 \%$ of the patients were alive, respectively. The median observation time was 116 months (range 30.5-205). Patients with response on day 7 and 28 had significantly higher OS probability than non-responders with an OS rate after two years of 49 and $58 \%$, respectively. Overall survival and OS according to 

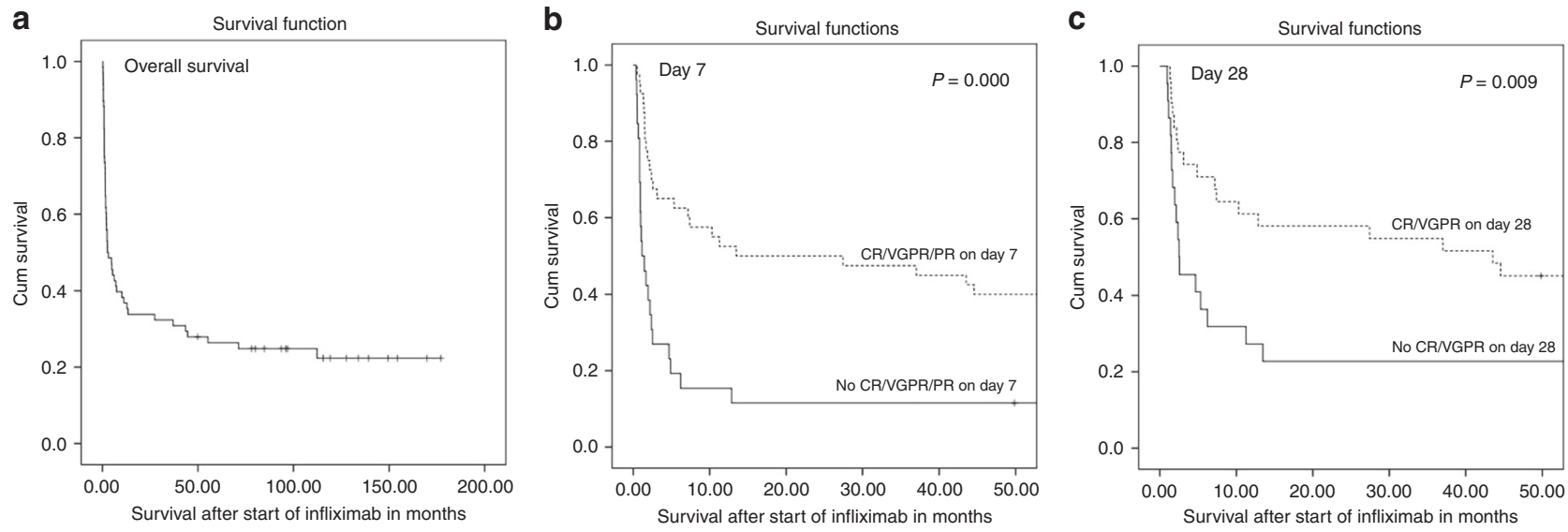

Fig. 2 Overall survival (a) and overall survival according to response status on day 7 (b) and day 28 (c)

Table 2 Causes of death

\begin{tabular}{ll}
\hline & $N(\%)$ \\
\hline Organ failure caused by GVHD & $20(38.5)$ \\
Infections & $17(32.7)$ \\
$\quad$ Invasive fungal $(N=8)$ & \\
$\quad$ Viral $(N=4)$ & \\
$\quad$ Bacterial $(N=3)$ & \\
$\quad$ Unspecified $(N=2)$ & $5(9.6)$ \\
Relapse & $4(7.7)$ \\
Multi-organ-failure & $6(11.5)$ \\
Other & \\
$\quad$ Cerebral hemorrhage $(N=3)$ & \\
Cancer pharynx $(N=1)$ & \\
$\quad$ Myocardial infarction $(N=1)$ & \\
$\quad$ Hepatic failure of unknown cause $(N=1)$ & \\
\hline
\end{tabular}

response are shown in Fig. 2. Patients with no more than PR on day 28 had OS comparable to patients with PD on day 28 (data not shown). In univariate analysis, higher grade of aGvHD, unrelated donor, and no response on day 7 and 28 were associated with poor survival. See supplemental Table 2. Causes of death are shown in Table 2.

\section{Infections}

Infections were observed in $61(90 \%)$ of the patients. Bacterial infections were seen in $45(66 \%)$, viral infections in $36(53 \%)$ and fungal infections in $35(52 \%)$ patients. The microbiological agents are listed in Table 3. There were 90 infectious episodes classified as severe (mean $=1.3$, range $=0-7$ ) and 32 life-threatening or fatal (mean $=0.47$, range $=0-2)$ in 53 patients. Number of severe or fatal infections pr. patient month were median 0.5 (range 0-5.36).

\section{Chronic GVHD}

Chronic GVHD occurred in 22 of the 34 patients who survived at least 3 months. Only four of the 16 patients still alive at the time of analysis were free from cGvHD. Median time to diagnosis of cGvHD from administration of infliximab was 30 weeks (range 16-108).

\section{Discussion}

In this study, we show that infliximab has effect in steroidrefractory or steroid-dependent aGvHD as it has also been shown previously. Patriarca et al. [20] reported on 32 patients with mainly severe aGvHD and found $19 \%$ of patients had CR and 40\% PR on day 7. Couriel et al. [21] evaluated 21 patients with primarily grade II steroidrefractory aGvHD and found response in $67 \%$ on day 7 . These day 7 responses are comparable to our day $7 \mathrm{CR} /$ VGPR/PR rate of $60 \%$ in patients with mainly severe aGvHD.

Pidala et al. [23] reported that only $15 \%$ of the patients treated with infliximab achieved CR at median 6 days (range 2-26). They concluded that infliximab may be of limited value in grade III-IV aGvHD. This is contradicted by our findings where the majority of patients also have severe aGvHD. The reasons for the poor results reported by Pidala et al. are not clear, but may be due to less intensive treatment or early response assessment. The PR rates are not stated in the study.

As shown by Martin et al. [1] results on second-line treatments are variable, but with most agents demonstrating some activity. Overall CR/PR rate for 29 studies was $58 \%$ but this should be interpreted with caution because the timing and definition of response varies, and furthermore there are differences in patient populations. Of the included studies, five reported response on day 28 with CR 
Table 3 Overview of the microbiological agents found in the patients during treatment with infliximab

\begin{tabular}{|c|c|c|c|c|c|c|c|}
\hline Blood & $\mathrm{N}$ & Sputum/BAL*fluid & $\mathrm{N}$ & Feces/intestine & $\mathrm{N}$ & Urine & $\mathrm{N}$ \\
\hline Gram-negative & & Gram-negative & & Gram-negative & & Gram-negative & \\
\hline Eschericia coli & 8 & Pseudomonas aeruginosa & 5 & Pseudomonas aerugiosa & 1 & E.coli & 2 \\
\hline Pseudomonas aeruginosa & 4 & Moraxhella catharalis & 3 & Aeromonas hydrophila & 1 & Klebsiella pneumoniae & 1 \\
\hline Klebsiella pneumoniae & 3 & Eschericia coli & 1 & Gram-positive & & Citrobacter freundii & 1 \\
\hline Listeria monocytogenes & 2 & Branhamella catharalis & 1 & Clostridium difficile & 19 & Gram-positive & \\
\hline Gram-positive & & Haemophilus influenzae & 1 & Yeast & & Enterococcus faecium & 3 \\
\hline Enterococcus faecalis & 6 & Legionella pneumophila & 3 & Candida albicans & 6 & Enterococcus faecalis & 1 \\
\hline Streptococcus pneumoniae & 2 & Pseudomonas putida & 1 & Candida parapsilosis & 3 & Yeast & \\
\hline Micrococcus luteus & 1 & Gram-positive & & Saccharamyces cerevisiae & 4 & Candida albicans & 1 \\
\hline Staphylococcus epidermidis & 7 & Staphylococcus aureus & 4 & Candida glabrata & 2 & Candida glabrata & 3 \\
\hline Staphylococcus aureus & 2 & Streptococcus pneumoniae & 2 & Candida krusei & 1 & Candida krusei & 1 \\
\hline Staphylococcuc haemolyticus & 1 & Enterococcus faecium & 3 & Unclassified yeast & 4 & Candida parapsilosis & 2 \\
\hline Koagulase-negative coccus & 1 & Gram-positive coccus & 1 & Virus & & Unclassified yeast & 1 \\
\hline Non-hemolytic streptococcus & 1 & Moulds & & Cytomegalovirus & 10 & Virus & \\
\hline Yeast & & Aspergillus fumigatus & 11 & Rotavirus & 1 & Polyomavirus & 5 \\
\hline Candida albicans & 2 & Candida albicans & 2 & Adenovirus & 1 & & \\
\hline Candida parapsilosis & 1 & Candida glabrata & 2 & Norwalkvirus & 1 & & \\
\hline Candida glabrata & 3 & Virus & & & & & \\
\hline Virus & & Influenza A & 2 & & & & \\
\hline Cytomegalovirus & 17 & Respiratory syncytial virus & 2 & & & & \\
\hline \multirow[t]{5}{*}{ Epstein Barr virus } & 2 & Parainfluenza & 2 & & & & \\
\hline & & Cytomegalovirus & 1 & & & & \\
\hline & & Corona virus & 1 & & & & \\
\hline & & Boca virus & 1 & & & & \\
\hline & & Metapneumovirus & 1 & & & & \\
\hline $\mathrm{CNS}$ & & Skin & & Liver & & & \\
\hline Gram-negative & & Gram-positive & & Moulds & & & \\
\hline Listeria monocytogenes & 1 & Staphylococcus aureus & 1 & Aspergillus fumigatus & 1 & & \\
\hline Moulds & & Yeast & & & & & \\
\hline Aspergillus fumigatus & 2 & Trichosporon mucoides & 1 & & & & \\
\hline Virus & & Virus & & & & & \\
\hline Cytomegalovirus & 1 & Varicella zoster virus & 1 & & & & \\
\hline
\end{tabular}

*BAL broncho-alveolar lavage

proportions between $0.08-0.42$ and only two reported response on day 7 with CR/PR proportions of 0.83 and 0.67 .

None of the suggested therapies have proved superior to others. Therefore, we adhered to the recently proposed guidelines for response assessment in aGVHD [4, 27] to facilitate comparison both within studies on infliximab but also with other therapeutic options in the absence of large randomized, controlled studies.

Patients treated with second-line therapy for aGvHD have dismal prognoses with a 6 month survival estimate of 0.49 [1]. We confirm this finding with high early mortality with only $44 \%$ of the patients alive after 6 months.
Response assessment on day 7 and 28 has primarily been tested in first-line aGvHD treatment where especially response on day 28 is shown to correlate strongly with longterm endpoints including survival [27-29]. For second-line treatment, it is important to have an early predictor of treatment success such as response on day 7. With this study, we validate that both having $\mathrm{CR}$, VGPR or PR on day 7 and having either CR or VGPR on day 28 are predictive of survival. We hypothesized that having only PR by day 28 after second-line therapy indicates insufficient treatment effect. This was confirmed as patients with PR on day 28 had OS comparable to patients with PD on day 28. Early identification of patients with a dismal prognosis is 
important in aGvHD, because alternative therapy should be initiated as soon as possible.

We found low incidence of relapse, but infections were a substantial problem with $78 \%$ of patients having severe and/ or fatal infections despite prophylactic antimicrobial medication. Marty et al. [30] previously reported increased incidence of non-Candida invasive fungal infections in patients treated with infliximab for aGvHD, which is in line with our observation of invasive Aspergillus infections. Carcía-Cadenas et al. [31] found 1-year incidence or bacterial, viral and fungal infections to be respectively 74, 65 and $14 \%$ after second-line treatment of aGvHD with anticytokine therapy. Whether patients treated with infliximab have additional, different, or more severe infections compared to other treatments, cannot be concluded from these data. Careful monitoring of the patients, including relevant sampling and clinical microbiological diagnosis as well as early, aggressive antibiotic treatment, is pivotal.

The results from the present study are limited by the retrospective nature, the heterogeneity of patients and their aGvHD-treatment. Before infliximab was initiated, the patients had been affected by aGvHD for variable periods of time and were on variable systemic immunosuppression. Both steroid-refractory and steroid-dependent patients were treated with infliximab and it is possible that treatment schedules and/or duration should be different for these different groups. The optimal treatment schedule for infliximab remains unknown.

Additional immunosuppression was administered to one fourth of the patients, and this could potentially account for responses or influence survival. However, it was the most severely affected patients who received additional therapy and we found that having additional therapy was associated with worse response on day 28 (seven of eight had PD or had died).

\section{Conclusion}

We validate, in the presently largest study on infliximab, that response on day 7 and 28 is able to identify high and low risk groups after second-or-further-line treatment. In patients with CR or VGPR on day $28,58 \%$ were alive after two years, which is encouraging considering the majority of patients had grade III-IV aGvHD. Our results are in line with previously published reports on infliximab and other second-line therapies. Further research, preferably prospective and controlled with comparable endpoints, is warranted. Patients who fail to respond should be identified early and offered alternative therapies.

Acknowledgements Supported by unrestricted grants from the Novo Nordisk Foundation (NNF15OC0014158) and the Danish Cancer Society.

\section{Compliance with ethical standards}

Conflict of interest: The authors declare that they have no conflict of interest.

\section{References}

1. Martin PJ, Rizzo JD, Wingard JR, Ballen K, Curtin PT, Cutler C, et al. First- and second-line systemic treatment of acute graftversus-host disease: recommendations of the American Society of Blood and Marrow Transplantation. Biol Blood Marrow Transpl. 2012;18:1150-63.

2. Martin PJ, Inamoto Y, Flowers MED, Carpenter PA. Secondary treatment of acute graft-versus-host disease: a critical review. Biol Blood Marrow Transpl. 2012;18:982-8.

3. Martin PJ. Study design and endpoints in graft-versus-host disease. Best Pract Res Clin Haematol. 2008;21:357-72.

4. Martin PJ, Bachier CR, Klingemann H-G, McCarthy PL, Szabolcs P, Uberti JP, et al. Endpoints for clinical trials testing treatment of acute graft-versus-host disease: a joint statement. Biol Blood Marrow Transpl. 2009;15:777-84.

5. Sengsayadeth S, Savani BN, Jagasia M, Goodman S, Greer JP, Chen $\mathrm{H}$, et al. Six-month freedom from treatment failure is an important end point for acute GVHD clinical trials. Bone Marrow Transpl. 2014;49:236-40.

6. Inamoto Y, Martin PJ, Storer BE, Mielcarek M, Storb RF, Carpenter PA. Response endpoints and failure-free survival after initial treatment for acute graft-versus-host disease. Haematologica. 2014;99:385-91.

7. Remberger M, Ringden $\mathrm{O}$, Markling L. TNF alpha levels are increased during bone marrow transplantation conditioning in patients who develop acute GVHD. Bone Marrow Transpl. 1995;15:99-104.

8. Korngold R, Marini JC, De Baca ME, Murphy GF, Giles-komar J. Role of tumor necrosis factor alpha in graft-versus-host disease and graft-versus-leukemia responses. Biol Blood Marrow Transpl. 2003;303:292-303.

9. Choi SW, Stiff P, Cooke K, Ferrara JLM, Braun T, Kitko C, et al. TNF-inhibition with etanercept for graft-versus-host disease prevention in high-risk HCT: lower TNFR1 levels correlate with better outcomes. Biol Blood Marrow Transpl. 2012;18:1525-32.

10. Hamadani M, Hofmeister CC, Jansak B, Phillips G, Elder P, Blum W, et al. Addition of Infliximab to standard acute graftversus-host disease prophylaxis following allogeneic peripheral blood cell transplantation. Biol Blood Marrow Transpl. 2008;14:783-9.

11. Alousi AM, Weisdorf DJ, Logan BR, Bolan J, Carter S, Difronzo N, et al. Etanercept, mycophenolate, denileukin, or pentostatin plus corticosteroids for acute graft-versus-host disease: a randomized phase 2 trial from the Blood and Marrow Transplant Clinical Trials Network. Blood. 2009;114:511-7.

12. Uberti JP, Ayash L, Ratanatharathorn V, Silver S, Reynolds C, Becker M, et al. Pilot trial on the use of etanercept and methylprednisolone as primary treatment for acute graft-versus-host disease. Biol Blood Marrow Transplant. 2005;11:680-7.

13. Levine JE, Paczesny S, Mineishi S, Braun T, Choi SW, Hutchinson RJ, et al. Etanercept plus methylprednisolone as initial therapy for acute graft-versus-host disease. Blood. 2008;111:2470-5.

14. Couriel DR, Saliba R, de Lima M, Giralt S, Andersson B, Khouri I, et al. A phase III study of infliximab and corticosteroids for the initial treatment of acute graft-versus-host disease. Biol Blood Marrow Transpl. 2009;15:1555-62. 
15. Gatza E, Braun T, Levine JE, Ferrara JLM, Zhao S, Wang T, et al. Etanercept plus topical corticosteroids as initial therapy for grade one acute graft-versus-host disease after allogeneic hematopoietic cell transplantation. Biol Blood Marrow Transpl. 2014;20:1426-34.

16. Herve BP, Flesch M, Tiberghien P, Wijdenes J, Racadot E, Bordigoni P, et al. Phase I-II Trial a Monoclon Anti-Tumor Necrosis Factor. Blood. 1992;79:3362-8.

17. Kobbe G, Schneider P, Rohr U, Fenk R, Neumann F, Aivado M, et al. Treatment of severe steroid refractory acute graft-versus-host disease with infliximab, a chimeric human/mouse antiTNFalpha antibody. Bone Marrow Transpl. 2001;28:47-9.

18. Rivkina AM, Stump LS. Infliximab in graft-versus-host disease. Am J Health Syst Pharm. 2002;59:1271-5.

19. Yamane T, Yamamura R, Aoyama Y, Nakamae H, Hasegawa T, Sakamoto C, et al. Infliximab for the treatment of severe steroid refractory acute graft-versus-host disease in three patients after allogeneic hematopoietic transplantation. Leuk Lymphoma. 2003;44:2095-7.

20. Patriarca F, Sperotto A, Damiani D, Morreale G, Bonifazi F, Olivieri A, et al. Infliximab treatment for steroid-refractory acute graft-versus-host disease. Haematologica. 2004;89:1352-9.

21. Couriel D, Saliba R, Hicks K, Ippoliti C, de Lima M, Hosing C, et al. Tumor necrosis factor-alpha blockade for the treatment of acute GVHD. Blood. 2004;104:649-54.

22. Sleight BS, Chan KW, Braun TM, Serrano A, Gilman A L. Infliximab for GVHD therapy in children. Bone Marrow Transpl. 2007;40:473-80.

23. Pidala J, Kim J, Field T, McBride A, Kharfan-Dabaja M, Perkins $\mathrm{J}$, et al. Infliximab for managing steroid-refractory acute graft-versus-host disease. Biol Blood Marrow Transpl. 2009;15:1116-21.
24. Rao K, Rao A, Karlsson H, Jagani M, Veys P, Amrolia PJ. Improved survival and preserved antiviral responses after combination therapy with daclizumab and infliximab in steroidrefractory graft-versus-host disease. J Pediatr Hematol Oncol. 2009;31:456-61.

25. Yang J, Cheuk DKL, Ha SY, Chiang AKS, Lee TL, Ho MHK, et al. Infliximab for steroid refractory or dependent gastrointestinal acute graft-versus-host disease in children after allogeneic hematopoietic stem cell transplantation. Pediatr Transpl. 2012;16:771-8.

26. Przepiorka D, Weisdorf D, Martin P, Klingemann HG, Beatty P, Hows J, et al. 1994 consensus conference on acute GVHD grading. Bone Marrow Transpl. 1995;15:825-8.

27. MacMillan ML, DeFor TE, Weisdorf DJ. The best endpoint for acute GVHD treatment trials. Blood. 2010;115:5412-7.

28. Saliba RM, Couriel DR, Giralt S, Rondon G, Okoroji G-J, Rashid A, et al. Prognostic value of response after upfront therapy for acute GVHD. Bone Marrow Transpl. 2012;47:125-31.

29. Levine JE, Logan B, Wu J, Alousi AM, Ho V, Bolaños-Meade J, et al. Graft-versus-host disease treatment: predictors of survival. Biol Blood Marrow Transpl. 2010;16:1693-9.

30. Marty FM, Lee SJ, Fahey MM, Alyea EP, Soiffer RJ, Antin JH, et al. Infliximab use in patients with severe graftversus-host disease and other emerging risk factors of nonCandida invasive fungal infections in allogeneic hematopoietic stem cell transplant recipients: a cohort study. Blood. 2003;102:2768-76.

31. García-Cadenas I, Rivera I, Martino R, Esquirol A, Barba P, Novelli $S$, et al. Patterns of infection and infection-related mortality in patients with steroid-refractory acute graft versus host disease. Bone Marrow Transpl. 2017;52:107-13. 